\title{
CORRUPCIÓN, ÉTICA Y FUNCIÓN PÚBLICA EN EL PERÚ
}

\author{
ROLE OF CORRUPTION, ETHICS AND PUBLIC FUNCTION IN PERU \\ Jeri Gloria Ramón RuffNer* \\ Docente Principal de la Facultad de Ciencias Contables \\ Universidad Nacional Mayor de San Marcos-UNMSM / Lima-Perú \\ [Recepción: Marzo de 2014/ Conformidad: Mayo 2014]
}

\section{RESUMEN}

Las razones que nos han llevado a abordar esta problemática son claras, tomando en cuenta que la corrupción genera un impacto negativo en la consolidación de la democracia y de la gobernabilidad, además que subvierte las garantías de los ciudadanos, evadiendo el respeto a los derechos humanos y, en la ética ciudadana. Los actos de corrupción son prácticas nocivas que merecen un estudio adecuado de los problemas que genera y de los mecanismos adecuados jurídicamente para controlarlo. No podemos, dejar de lado que en nuestro país, la corrupción es percibida como una anomalía cotidiana, un quebrantamiento del funcionamiento normal de las instituciones, incluso como hechos propios de la idiosincrasia nacional. Esto evidentemente afecta la confianza del ciudadano en sus instituciones; además, que pervierte la ética pública, promoviéndose una moral laxa y una actitud pasiva. Esta investigación formula propuestas para combatir dichas prácticas en sus diversas formas, porque la corrupción tergiversa las condiciones mínimas de convivencia y la validez de las normas. Por ello, es que se quiere identificar aquellos efectos negativos que a la larga conducen a una actitud perniciosa que se halla caracterizada por la resignación, el escepticismo y el cinismo frente al marco legal e incluso ante la idea de la honradez como valor indispensable para el ejercicio de la función pública.

Palabras clave:

Corrupción de funcionarios; ética; política; función pública.

\begin{abstract}
The reasons that have led us to address this problem are cleartaking into account that corruption has a negative impact on consolidation of democracy and governance, also that subverts the guarantees of citizens, avoiding the respect for human rights and in civic ethics. Corruption are harmful practices that deserve an appropriate study of the problems and generates the appropriate legal mechanisms to control it. We can not, ignore the fact that in our country, corruption is perceived as a daily anomaly, a breach of the normal functioning of the institutions, even as facts themselves of national idiosyncrasies. This obviously affects public confidence in their institutions; also perverting public ethics, promoting lax moral and passive.

This research makes proposals to combat such practices in its various forms, because corruption distorts the minimum conditions of existence and the validity of the rules. Thus it is that we want to identify those negative effects that eventually lead to a pernicious attitude that is characterized by resignation, skepticism and cynicism about the legal framework and even at the idea of honesty as an indispensable value for the exercise of public functions.
\end{abstract}

\section{Keywords:}

Official corruption; ethics; policy; public function.

\footnotetext{
* Doctora en Contabilidad. Magister en Contabilidad con mención en Auditoría. Contadora Pública Colegiada - UNMSM. Email: jeriramon_162@hotmail.com
} 


\section{INTRODUCCIÓN}

Es importante configurar el problema de la corupción como un fenómeno principalmente político, pero que afecta a casi todas las órdenes o espacios vitales. El poder, tal como es entendido por la mayoría de personas, consiste en las facultades que detentan un grupo selecto o incluso una persona para ejercer su dominio sobre el resto. Es una cualidad adquirida y que solo se adjudica a un sector determinado y reducido. No son pocos los ejemplos históricos de un grupo de personas que obtuvieron dicho poder y a través de su lógica y dinámica, dominaron todos los asuntos de la sociedad, la política, la economía, entre otros, para beneficio propio, originándose desde la formación de las civilizaciones los actos de corrupción. Este poder a su vez pretende aparecer como legítimo, por lo cual muchas veces la voluntad de dominante trataba de disfrazarse en fórmulas legales, decisiones judiciales u órdenes administrativas. Estas situaciones provocaban la ruptura de las relaciones societarias y afectan el sistema de administración pública.

A raíz de la caída del régimen autoritario del ex presidente Fujimori en noviembre del año 2000, se develó una selecta red de corrupción que afectó a gran parte de las instituciones del país. Dicho grupúsculo había venido actuando sistemáticamente e involucró a los más altos funcionarios vinculados a dicho régimen. Luego de las denuncias públicas y las reacciones políticas, se propuso como medida la creación de un subsistema especializado, el sistema penal anticorrupción, el cual desde entonces ha realizado una serie de esfuerzos por investigar, juzgar y sancionar prácticas graves de corrupción cometidas durante dicho período, así como, aquellas que se han sucedido durante regímenes democráticos posteriores. Si bien, el balance puede ser considerado como positivo, el sistema penal anticorrupción adolece de un gran problema al no poder enfrentar adecuadamente muchas de las manifestaciones de la corrupción. En ese sentido, se han producido, en varios casos emblemáticos de corrupción, actuaciones fiscales o judiciales sin la debida fundamentación o con una concepción arbitrariamente hipergarantista que desnaturaliza los principios del proceso y favorece la impunidad de estos casos. Dicho sistema penal anticorrupción ha desarrollado una jurisprudencia sumamente interesante y de gran amplitud que ha suscitado un debate intenso entre los especialistas en derecho penal y los interesados en el control de la corrupción, sumando también las interpretaciones del Tribunal Constitucional sobre la materia.

En nuestro país, existen una serie de obras que han examinado dicho fenómeno desde un punto de vista exclusivamente jurídico. Recientemente, producto de diversos escándalos, se han desarrollado ensayos que han tratado de enmarcar debidamente las diferentes formas de corrupción en el Perú, atendiendo más a criterios históricos, filosóficos y sociológicos.

Para el desarrollo de este trabajo, se ha acudido tanto a fuentes extranjeras como nacionales, destacando entre dichas obras un estudio realizado en nuestro país por el Instituto de Democracia y Derechos Humanos que ha tenido en consideración una serie de artículos en torno a la corrupción. Dicha obra se titula "Estudios críticos sobre los delitos de corrupción en el Perú" (2012) y es la investigación más reciente que se ha realizado en nuestro país, desde un enfoque netamente jurídico.

\section{CORRUPCIÓN Y CULTURA POLÍTICA}

Continuamente los diferentes estudiosos plantean, utilizando diversos instrumentos para su estudio, la problemática de la corrupción cometida en la Administración Pública. Al respecto, se observa con preocupación en casi todos los ámbitos, el deterioro que viene confrontando la conducta de los funcionarios y funcionarias públicas en el ejercicio de su cargo, pues son mayores los hechos de corrupción cometidos, a pesar de los instrumentos legales aprobados para acabar con este flagelo.

La búsqueda de métodos eficaces para combatir la corrupción, es esencial para la promoción del desarrollo económico, la calidad de la democracia y la justicia social. Desde un punto de vista estructural, los efectos de la corrupción sobre el desarrollo económico, y más sobre un desarrollo económico sostenible, son demoledores. También, influye negativamente en el desarrollo de instituciones incentivadoras de equilibrios eficientes y equitativos. 
De manera general, la corrupción afecta negativamente al funcionamiento de la democracia y el Estado de derecho pues daña la igualdad política y el bien común. Algunas investigaciones señalan la corrupción como una de las variables causales de tal fenómeno de desafección, pues erosiona la confianza en el gobierno y la legitimidad de las instituciones políticas. En cuanto al rendimiento, un factor clave para explicar el deterioro en la percepción de confianza es el declive de la fidelidad o de la ética con la que los políticos actúan en representación de los ciudadanos. En cuanto al cambio de expectativas sociales, algunos autores consideran que una ciudadanía más educada y más escéptica es más rigurosa en el juicio a sus dirigentes, además de ser más sensible a cuestiones éticas.

En definitiva, la presencia de estos delitos en el seno de las sociedades tiene una vinculación directa con los valores que son defendidos por los ciudadanos. Con relación a los funcionarios, los valores se materializan a través de la ética profesional. Pues esta tiene como objeto crear conciencia de responsabilidad, en todos y cada uno de los que ejercen una profesión u oficio, pues, se requieren cualidades éticas, como la idoneidad o aptitud que le da un nuevo perfil a su personalidad. El ser profesional digno representa la excelencia, el decoro que tiene el funcionario y el respeto consigo mismo, configura la figura principal en el que debe girar su actuación, su conducta en cualquier ramo donde se desempeñe, de allí, lo relevante de éste análisis. Podemos señalar, entonces, que el elemento moral requiere también una gran atención en aras de un estudio integral de la corrupción, que reúna todos sus aspectos.

A pesar que muchos son los enfoques y disposiciones que amparan la formación del nuevo ciudadano con valores y principios éticos, el deterioro evidente en la actualidad es preocupante, sobre todo cuando se describen situaciones de funcionarios públicos, que en el ejercicio de sus funciones actúan en contra de ello, acrecentando esta problemática a todo nivel. Un estudio de Carbonell (2010), que analiza la situación judicial mexicana, destaca la importancia de la ética pública, aunada a una mejor política legislativa: "Una parte de la corrupción en el sistema judicial mexicano es producto de una falta de ética que evite que los agentes del Estado incurran en actos de deshonestidad. Pero también hay muchos actos de corrupción que tienen su origen en una mala política legislativa, es decir, a veces son las propias leyes las que generan o inducen a la corrupción”.

Por ello, surgen disposiciones en diversos instrumentos legales, que llevan consigo el control jurídico, para sancionar las diversas conductas cometidas en la administración pública por sus funcionarios, por encontrarse muchos casos, sin que hayan sido sancionados por los órganos jurisdiccionales, a pesar de haber sido imputados por el Ministerio Público. Este problema de la impunidad, se encuentra muy arraigado en la experiencia latinoamericana, tal como los reflejan los estudios internacionales sobre el impacto de la corrupción en estos países. . De allí, la necesidad de analizar estos delitos de corrupción y el control jurídico, que se aplica, en bienestar de los males que aquejan a los distintos países. En atención a la problemática expuesta, resulta interesante estudiarla profundamente.

\section{CORRUPCIÓN Y ÉTICA PÚBLICA}

El fenómeno de la corrupción está directamente vinculado con la idea de ética pública. Todo estudio que busque responder las causas y el impacto de la corupción debe entender primero ¿Qué es la ética pública? ¿Cuál es su importancia? ¿Por qué es necesaria? así como el identificar las acciones existentes para su fomento. Esta tarea no está exenta de dificultad, pues el concepto de ética ha sido discutido profundamente por diferentes corrientes. En términos generales, la ética o disciplina moral tiene por objeto el examen filosófico o la explicación de los llamados "hechos morales". De ese modo, en tanto disciplina, estudia las actitudes y costumbres del ser humano y las clasifica en virtudes y vicios, en acciones debidas e indebidas, convenientes y nocivas, con el fin de formar el carácter de los hombres al mostrar aquellos hábitos dignos de imitar (Brugger: 1969). La ética forja el carácter, esto significa que los seres humanos nacen con un temperamento innato, con un conjunto de sentimientos que no han elegido y resulta difícil modificar, pero que puede encauzarse a lo largo de su vida; por lo que, es posible ir adquiriendo un nuevo carácter. $\mathrm{El}$ individuo tiene que ir forjándose a sí mismo al elegir unas posibilidades vitales y rechazar otras.

Vol. 22(41) 2014 | QUIPURAMAVOC / 61 
Cabe distinguir entre la ética privada y la ética pública (Bustamante: 2006). La ética privada es definida, tomando en cuenta el sistema conceptual de Peces-Barba, una ética de contenidos y de conductas que señala el criterio para la salvación, la virtud, el bien o la felicidad, es decir, una ética que orienta los planes de vida de cada individuo como cauce directo para la humanización. Su camino y meta es alcanzar la autonomía moral del individuo. A diferencia del anterior, la ética pública es el conjunto de objetivos o de fines que se consideran debe realizar el poder político a través de su Derecho, teniendo como meta el desarrollo integral de cada persona. Ella establece criterios, guías para que los espacios sociales y los ámbitos del poder y del Derecho sean racionales y estén abiertos a la realización de proyectos de humanidad.

En vista de lo anterior, la ética, al referirse al ámbito público, implica necesariamente relacionarse con la política y no se limita a los funcionarios públicos. Un buen gobierno no solo requiere funcionarios responsables sino también políticos responsables, puesto que son éstos últimos principalmente quienes gozan del máximo margen de autonomía en las decisiones y de estas decisiones depende a su vez la actuación de los principios.

Bajo estas premisas, la corrupción es la contraparte de una acción ética. Con fundamento en la disciplina ética esta investigación concibe a la corrupción como un mal ya que se compone de una serie de actos indebidos por parte de ciertas autoridades políticas. Sin duda, históricamente, la corrupción política ha sido objeto de reproche moral en todas las sociedades, los testimonios de las diferentes culturas así lo prueban, afectando la imagen institucional en donde se practique.

De modo latente, en la opinión pública, existe la idea de que en la política y en el gobierno existe corrupción y que quienes participan en este ámbito son corruptos. Esta opinión demuestra que o bien se han olvidado o bien se ignoran los fines de la política y la importancia de la ética dentro de la función pública. Esta situación invita a los estudiosos de los asuntos públicos a replantearse la necesidad de llevar a cabo estudios destinados a fortalecer la ética en políticos y funcionarios públicos.
El fomento de la ética en los servidores públicos es un elemento que auxilia para lograr concienciar en sólidos principios de conducta ética y así generar una mayor excelencia en la calidad y gestión de los intereses colectivos. El comportamiento correcto de los gobernantes es una condición sine qua non para que exista una eficiente administración. Asimismo, la ética pública es un elemento importante para hacer contrapeso no solo a la corrupción sino a las distintas actitudes antiéticas al inyectar un conjunto de principios y valores y así revitalizar por un lado a las instituciones públicas y por otro a los servidores públicos, entendiendo como tales a aquellas personas que ocupan un cargo público y sirven al Estado: políticos y funcionarios. La ética es el ingrediente adicional para hacer más sólido el dizque que contenga el mar de corrupción.

Integrar los elementos de la ética pública en las herramientas administrativas es importante para hacer frente a los problemas de ineficiencia, corrupción y desconfianza que padecen los gobiernos y administraciones públicas del mundo a fin de lograr el desarrollo de una cultura política y administrativa que acompañe a los gobernantes y funcionarios. Cualquier gobierno estará legitimado en la medida en que defienda una verdadera ética pública en virtud de que ésta conlleva responsabilidad, espíritu de servicio y atención al ciudadano.

\section{DEMOCRACIA Y CORRUPCIÓN EN AMÉRICA LATINA}

Un repaso general sobre la literatura especializada que trata el tema de la cultura política nos ha permitido reconocer decenas de definiciones, unas sintéticas y otras descriptivas. De todas ellas, una que resulta interesante es aquella que destaca como componente pri $\neg$ mario y substancial de la cultura política al comportamiento en el ámbito público y que está referido directamente con las relaciones de poder.

Cabe aclarar que dentro de la 'noción de comportamiento', por una parte, se encierran valores, ideas y patrones que se encuentran vigentes en una sociedad; $y$, por otra parte, es esa 'noción' la que permite que el concepto sea utilizado como variable explicativa de las relaciones entre ciudadanos e instituciones polí- 
ticas en el marco de un proceso político particular. Esto nos permite, a nivel empírico, poder identificar cuáles son los rasgos más rescatables de los distintos sistemas políticos y su relación con la corrupción.

En primer lugar, la noción de corrupción está vinculada directamente con el nacimiento de las instituciones políticas, y en particular con la existencia de los sistemas democráticos. Su consecuencia más relevante es que desemboca en un proceso de exclusión. Pero también que existe una relación de funcionalidad entre la corrupción y el modelo económico que se siga. Así, por ejemplo, la corrupción hace a la esencia de la sociedad capitalista actual y es especial manifestación de la crisis del sistema. A pesar de ello, es común que los estudios centren su atención en el componente político de la corrupción, pues es el que ha captado más la atención de los estudios sociales en virtud de los vaivenes del poder y su interrelación con las desigualdades sociales (que también incluyen factores económicos): "La corrupción es un tema recurrente en el debate político. El concepto de corrupción ha sido usado desde la antigüedad clásica griega y romana para referirse a la vida política. Por ejemplo, en las obras de Platón y en los escritos de Catón y Juvenal encontramos continuas referencias a la corrupción de las costumbre públicas y privadas. El mismo Maquiavelo, gran estudioso de la antigüedad y astuto observador de su tiempo, llegó a plantear con singular talento el vínculo que existía entre la corrupción de los gobernantes y los gobernados y nos quiso explicar cómo en aquellos casos en que la corrupción alcanza principalmente a los gobernantes ésta puede combatirse por medio del cambio político. Maquiavelo también observó con singular agudeza como la desigualdad social puede fomentar la corrupción".

En nuestro tiempo, el principal hecho político en América Latina es el hecho de la democracia. Ella prevalece en casi toda la región por primera vez en su historia; y más allá de los matices, variedad y desplazamientos, ella es una realidad, al menos en cuanto forma, en cuanto procedimiento. El sistema democrático aplicable a estos países se caracterizan por: a) elecciones periódicas para elegir a los representantes encargados de decisiones colectivas, b) en las elecciones los candidatos compiten libremente por votos, y c) toda la población adulta tiene derecho a votar. Sin embargo, la percepción de los ciudadanos sobre la práctica democrática dista de un sentimiento de satisfacción. En verdad, se identifica más bien como un malestar (Ruiz-Tagle: 1998).

El comportamiento político en América Latina se basa en una serie de rasgos de la conducta socialy política que se cristalizan a lo largo de su evolución histórica y son distinguibles de la conducta social y política de otras regiones del mundo. Esto es en realidad lo que nos permite reconocer la existencia de cultura política latinoamericana.

Contemporáneamente, muchos de los Informes anuales presentados por Organizaciones de Justicia Mundial (World Justice Project), con sede en Washington, revelan que la corrupción en los países latinoamericanos está muy difundida, siendo considerado como un comportamiento habitual tanto entre los servidores públicos como por los administrados.

Este documento revela que la falta de transparencia de las instituciones yla ineficiencia del sistema de justicia criminal son los problemas que hacen caer a muchos países latinoamericanos en los últimos lugares de la lista del informe internacional. Entre los países con mayores problemas, se encuentran Venezuela y México, criticados por sus sistemas de justicia inequitativos y al aureola de protección con que cuentan muchos de los infractores. Argentina y Colombia también recibieron malas calificaciones en materia de responsabilidad gubernamental e interferencia política. En el caso de Colombia, reviste particular importancia los problemas significativos relacionados con abusos policiales o violaciones de derechos humanos.

En el caso del Perú, la corrupción es un grave problema que enfrenta a nuestra sociedad desde los inicios de la Colonia. La historia reciente del Perú ha puesto de relieve, de manera dramática, que se trata de un problema latente para nuestra aún incipiente institucionalidad democrática. Sin duda, la corrupción socava las bases de las instituciones democráticas y la legitimidad del Estado, perjudicando la confianza que depositan los ciudadanos en las diferentes actuaciones de la Administración Pública: “( ... ) pese al logro de importantes avances en este ámbito, la impunidad de los delitos de corrupción, sobre todo 
de aquellos ligados al poder, ha sido una constante. A esta situación contribuyen una serie de factores como la posición económica y social de sus autores, sus conocimientos del sistema de justicia y la consecuente facilidad para evadirla, la posición de poder que ocupan los funcionarios públicos y el despliegue de sus influencias para impedir la investigación de los delitos, entre otras condicionantes. En este contexto, la impunidad por prescripción ha cobrado especial relevancia. Es frecuente ver que los procesos penales se ven truncados por imperio de la prescripción, y generan en la sociedad una sensación de impunidad generalizada de los actos de corrupción. Se escucha frecuentemente: «Roban al Estado, dilatan sus procesos y salen libres a disfrutar el fruto de su delito»”. (Pariona: 2012).

\section{NOCIÓN DE CORRUPCIÓN}

Realizando un análisis lingüístico de la palabra "corrupción", proviene del latín rumpere, que significa romper, dividir, quebrar, violar, anular; que a su vez se deriva de corrumpere, cuyo significado es alteración, desunión, descomposición. Corrumpere, entonces, debería significar: "romper con", "romper en unión de", pero en realidad quiere decir "echar a perder, pudrir". Por lo tanto, la expresión corromper siempre reconoce, en líneas generales, la presencia de dos partícipes en el acto, que se corresponden principalmente con dos espacios; el corruptor y el corrupto, es decir la fuerza que corrompe y aquella persona sobre el que recae y que, en definitiva, es lo que se echa a perder, lo que se pudre.

Sus defensores creen en que aspectos de moral, de espíritu o de mística para el progreso económico sin límites hallan campo propicio para la corrupción, y se suele instalar en este modelo político en que vivimos para formar parte de la llamada criminalidad no convencional acompañada por el abuso de poder. Pero no sólo por el abuso gubernamental que pueda existir, sino también el económico, el financiero, el industrial, el bancario, el tecnológico y el científico.

Uno de los componentes principales para la definición de corrupción es el relativo a la afectación de intereses públicos. Tal como afirma Carretero (2010), bajo la idea de que el servidor público tiene que en- contrarse al servicio de intereses generales, los códigos de ética han diseñado un conjunto de principios y reglas que debe guiar la función pública. Por ende, podemos definir a la corrupción como la negación de lo anterior, que se manifiesta precisamente en: No seguir intereses generales; Favorecer intereses particulares o indirectos; Favorecer los intereses de un tercero y Utilizar la legalidad o el fraude de la ley, o la insuficiencia de la ley para ello desde un cargo público.

Por ello, es de suma importancia para entender el fenómeno de la corrupción que se vea la diferencia entre la violación de un sistema de reglas vigente y la violación de un sistema de reglas morales con pretensiones de universalidad. Este último funcionaría como sistema normativo crítico y justificante del sistema de reglas vigente. Creo que comprender esta diferencia previene del peligro de solapar ambos niveles normativos y terminar creyendo que lo que es, es lo que debe ser. Cuando esto sucede, la corrupción llega a naturalizarse, de tal manera en el sistema de reglas vigente que la idea de un buen político, por ejemplo, termina siendo la idea de un político corrupto, astuto, virtuosamente maquiavélico" (Vásquez: 2010).

En consecuencia, cabe definir corrupción como el abuso de posición ejercitado por un servidor o funcionario público, con un beneficio extraposicional directo o indirecto (para el corrupto o de los grupos del que forma parte este), con incumplimiento de normas jurídicas que regulan el comportamiento de los servidores públicos (Villoria y Jiménez: 2012). Si bien esta definición es parcial, nos permite identificar un campo determinado de estudio, en consonancia con los tipos penales que regulan estos delitos contra la Administración Pública.

De la anterior definición, podemos complementar con varios elementos que vale traer a colación. Primero, corrupción es un problema social, esto quiere decir que se encuentra adherida a las distintas estructuras sociales. Segundo, y como se ven con detenimiento en el tema de la caracterización de la corrupción, esas estructuras sociales, en donde se presentan los actos de corrupción, están determinadas, a su vez, por subestructuras de poder. En tercera instancia, y por tradición se hablaba de corrupción como problema acontecido desde la administración pública 
frente a terceros, pero existe otra gran vertiente que se extiende en el sector privado, principalmente, en los grupos que resguardan grandes intereses económicos. Como punto cuarto, desde una concepción legalista, podría construirse una definición de corrupción que involucre entre otros elementos: conducta ilícita, que consiste en el mal uso del poder público o privado en beneficio propio o de terceros. Lo anterior, tendría como primera consecuencia, el visibilizar el sector privado de manera definitiva y efectiva.

Es importante diferenciar entre la corrupción directa y de la otra parte, la corrupción institucionalizada. Se habla de corrupción directa cuando en los comportamientos concretos e individuales, los autores, las víctimas, el objeto y los móviles pueden ser identificados o determinados claramente. Esto es posible, sobre todo, en el nivel inferior o intermedio de la jerarquía administrativa. Esto se debe a que las tareas de los funcionarios y servidores de este nivel consisten básicamente en ejecutar las decisiones tomadas por los altos funcionarios. En cuanto a la corrupción institucionalizada se caracteriza por su naturaleza oculta o disimulada y forma parte de la estructura institucional. Es difícil establecer un vínculo entre las causas y los efectos. De igual forma, resulta interesante poner de relieve una característica de la corrupción en un sentido criminológico.

No debemos dejar de lado que la actividad delictiva varía según las circunstancias de tiempo, lugar y evaluación moral del acto ilícito. Por tal motivo, el funcionario público en algunas ocasiones no alcanza a comprender realmente la criminalidad del acto y su propia actividad lo lleva a distorsionar la realidad de los hechos, creyendo que su jerarquía lo autoriza a proceder en forma natural, sin siquiera observar que su conducta ha quedado tipificada penalmente.

\section{CORRUPCIÓN Y FUNCIÓN PÚBLICA}

Hemos identificado la corrupción como aquella desviación por parte de la administración de los poderes del Estado del correcto funcionamiento, que no es otro que el "interés público". A su vez, hemos recalcado que existe un grupo de autores que extienden los alcances de este concepto al ámbito privado. No obstante, resulta materialmente más perjudicial la corrupción en su sentido publicista, pues implica una conducta se desvía de las obligaciones de orden público normales debido a intereses personales (familiares o de allegados) o beneficios monetarios o de orden social; o que viola normas respecto al uso de cierto tipo de influencias con fines personales.

Por lo tanto, la imputación hacia una persona como "corrupto" va asociada a la idea de que aquel esté en vinculación directa con la administración de los poderes del Estado, y no podría hablarse de corrupción en sentido estricto fuera del ámbito de la función pública, esto es, en términos domésticos, familiares o cotidianos.

En orden a estas ideas, por los términos "funcionario público" $y$ "empleado público" se suele designar a todo el que participa accidental o permanentemente del ejercicio de funciones públicas, sea por elección popular o por nombramiento de autoridad competente". Etimológicamente, esta palabra proviene del latín functionis que equivale a "servicio público".

Así, la Convención Interamericana contra la Corrupción establece en su artículo $1^{\circ}$ lo siguiente: Para los fines de la presente Convención, se entiende por:

"Función pública", toda actividad temporal o permanente, remunerada u honoraria, realizada por una persona natural en nombre del Estado o al servicio del Estado o de sus entidades, en cualquiera de sus niveles jerárquicos.

"Funcionario público", "Oficial Gubernamental” o "Servidor público", cualquier funcionario o empleado del Estado o de sus entidades, incluidos los que han sido seleccionados, designados o electos para desempeñar actividades o funciones en nombre del Estado o al servicio del Estado, en todos sus niveles jerárquicos".

Una definición más puntual sobre el tema señala que función pública debe ser entendida como aquella que monopólicamente ejerce el Estado a través de sus elementos específicamente designados y sólo por excepción delegada a particulares. Por otra parte, no hay que olvidar que el ejercicio de la función pública está directamente ligado a la existencia de una potestad administrativa, que, a pesar de ser considerado un poder jurídico, no deja de estar conectado con el ejercicio del poder político. 
Para entenderlo mejor, cabe entender por Administración Pública al conjunto de órganos al que por ejercicio directo o delegado del poder público, le compete preferentemente la realización de la función administrativa, entendida ésta última como la actividad jurídica del Estado, consistente en la ejecución de normas generales preestablecidas. $\mathrm{Al}$ respecto, del concepto de Administración pública se observa el emparentamiento de la función pública y el poder, toda vez que ella tiene que ver con personas o con organizaciones de personas con intereses comunes (grupos de poder).El poder lleva implícita una suerte de influencia sobre otros, que someten su voluntad y tiene un sentido de posesión. Es evidente que la satisfacción de esos deseos podría acarrear excesos $y$ afectar intereses de otros.

Acotada la noción de función pública, podemos definir al funcionario público como aquella persona que por disposición de la ley, nombramiento de autoridad competente u otro método establecido por normas de derecho público, presta servicios, generalmente permanentes $y$ remunerados, en los poderes del Estado, municipios o entes públicos. El funcionario actúa naturalmente por el Estado; sea representándolo; sea por una delegación de facultades que el propio Estado realiza, a los fines de que lleve a cabo la misión que se le encomienda en una determinada área. El funcionario ad hoc, que puede ser un empleado o un particular, resulta ser una excepción hasta cierto punto, ya que sus atribuciones, investidura y límite de actuación, reconocen origen en una ley que lo inviste de tal carácter. En todo caso, no resulta cierto que la ley penal trata a los funcionarios y servidores públicos del mismo modo que al ciudadano común, y este mayor rigor tiene relación directa con la responsabilidad social que representa el hecho de encarnar a la autoridad y el valor e interés social de preservar la preeminencia de la administración frente a los administrados.

Hay muchos tipos de corrupción que se pueden caracterizar de acuerdo a la dinámica del acto corrupto (si es un acto unilateral o involucra a muchas partes); los agentes involucrados (de alto nivel, de bajo nivel o agentes privados), el tamaño de la corrupción (corrupción mayor o menor), y las funciones públicas afectadas (ingresos o gastos, tareas administrativas). A continuación se discuten los tipos de corrupción más comunes en la literatura jurídica, para lo cual primero lo clasificaremos en orden a los ámbitos en que se presenta:

a) Corrupción política: La corrupción que más se expone en los medios noticiosos a través del mundo es la de naturaleza política. Se origina y crece dentro del seno del poder del Estado. El Estado es el que organiza un sistema de corrupción de carácter nacional. Esta corrupción se alimenta del debilitamiento de las instituciones sociales y a su vez aporta a ese mismo debilitamiento. La corrupción política implica una estructura organizativa del y desde el Estado. En este tipo de corrupción, el Estado es capturado por funcionarios de alto nivel. Las leyes, reglamentaciones y la política pública se determinan a base de influencias indebidas, pagos o regalías.

b) Corrupción administrativa: Esta altera la implantación de reglamentaciones, leyes y políticas para el beneficio de alguien o de algunos y es realizada por personas actuando en su carácter particular. Puede involucrar el que el funcionario público requiera pagos por recibir servicios públicos, por recibir contratos con gobierno, la venta de influencias, o pagos para ser privilegiado en las leyes o regulaciones.

c) Corrupción mayor y "petty corruption": La corrupción también se ha catalogado de acuerdo al tamaño del dinero involucrado y/o si es practicada por altos o bajos funcionarios. La corrupción mayor involucra grandes cantidades de dinero, esquemas elaborados y altos funcionarios. Este tipo de corrupción puede ser administrativa o política. Dependiendo de cuán común sea, la corrupción mayor puede resultar en la "captura del Estado" por parte de los intereses privados. La corrupción menor ("petty corruption") es corrupción de funcionarios políticos de menor nivel y generalmente involucra cantidades pequeñas de dinero, favores o regalos. Esta es la corrupción enfrentada en transacciones comunes por el ciudadano común al tratar de recibir servicios del gobierno o al encontrarse en la necesidad de realizar transacciones con el gobierno o sus oficiales. La corrupción menor no se ata a ningún partido político o persona en el poder.

66/ QVIPURAMAYOC | Vol. 22(41) 2014 
Puede pasar inadvertida por los funcionarios de jerarquía mayor o por los mismos empleados que trabajan junto al empleado corrupto.

Se puede señalar, que la modalidad de corrupción más conocida es la que se da a través de sobornos entre una empresa privada y un funcionario público, y donde usualmente median otorgamientos de contratos. La mayoría de los casos que han llegado a los tribunales y ciertamente los más notables, caen dentro de esta categoría. Pero la corrupción no solamente se da en el proceso de contratación de servicios y lo más probable es que muchos actos corruptos nunca son conocidos. Aunque la corrupción tiende a asociarse con transacciones de dinero, las transacciones monetarias son solo una expresión de ciertos actos de corrupción donde está de por medio el uso de propiedad pública y fondos del gobierno. La corrupción pública en su forma más amplia se refiere a acciones de fraude, abuso, desperdicio o incumplimiento que resultan en el mal uso de los recursos del gobierno y que socavan la confianza de los ciudadanos en las instituciones públicas. Bajo esta definición son muchas las situaciones en el día a día de la gestión pública en donde pueden darse actos de corrupción.

Otro proceso de las labores públicas donde se ha detectado corrupción es en la contratación de empleados. En este caso se puede dar nepotismo (contratación de familiares) o padrinazgo (contratación a base de conexiones políticas). En los procesos de compras y facturación, también puede darse corrupción en la forma de malversación de fondos. Se pueden hacer compras ficticias, compras a proveedores a cambio de pagos, o sobrefacturación cuya diferencia termina en los bolsillos del empleado público.

En conclusión, podemos exponer una clasificación que recoja los distintos matices del acto de corrupción: Abuso de funciones; Comisiones y obsequios ilegales; Contribuciones ilegales; Evasión o fraude; Cohecho y Nepotismo.

\section{CAUSAS E IMPACTO DE LA CORRUPCIÓN}

Causas afectivas. La causa primera de la que a su vez se derivan los deseos y pasiones para realizar actos de corrupción es la ignorancia. Ésta no se refiere a que los hombres que detentan un cargo sean ingenuos o faltos de instrucción respecto a las decisiones que toman, sino que se entiende como la falta de comprensión para llegar a la virtud o excelencia. Si bien, este componente tiene un carácter marcadamente moral, no debemos olvidar que también se puede dar por un desconocimiento de los alcances de una regla originada convencionalmente, lo cual representa en todo caso una causa formal y no afectiva.

Causas formales. De acuerdo con Rowland (1998), las causas formales se desprenden de la delimitación técnica del término y son: La falta de una clara delimitación entre lo público y lo privado, La existencia de un ordenamiento jurídico inadecuado a la realidad nacional, y La inoperancia práctica de las instituciones públicas.

Causas materiales. Se refieren a situaciones concretas que dan lugar a prácticas corruptas, En este caso son las distintas brechas existentes entre el orden jurídico y el orden social vigente, tales como: La brecha existente entre las necesidades reales de control político y las condiciones formales de ejercicio del poder; La brecha existente entre la dinámica del mercado y la intervención pública; La brecha existente entre el poder social efectivo y el acceso formal a la influencia política. y; La brecha existente entre los recursos de la administración pública y la dinámica social.

Causas culturales. Es necesario señalar que el concepto que se maneja hace referencia a la cultura política de un país, es decir al conjunto de actitudes, normas y creencias compartidas por los ciudadanos y que tienen como objeto un fenómeno político (en este caso la corrupción). Permiten así delimitar la extensión de las prácticas corruptas, la probabilidad de su ocurrencia y el grado de tolerancia social con que pueden contar.

\section{IMPACTO DE LA CORRUPCIÓN}

Rowland menciona que Dieter Frisch, ex-Director General de Desarrollo de la Comisión Europea, ha observado que la corrupción aumenta los costos de los bienes y servicios; incrementa la deuda de un país (y ello conlleva los futuros costos recurrentes); conduce al relajamiento de las normas de modo que se adquieren bienes que no alcanzan las normas es- 
tablecidas o tecnología inapropiada o innecesaria; y puede resultar en la aprobación de proyectos basados en el valor del capital involucrado en los mismos, más que en la mano de obra (lo que es más lucrativo para el que comete la corrupción), pero puede ser menos útil desde el punto de vista del desarrollo. Frisch señala que cuando un país aumenta su endeudamiento para llevar a cabo provectos que no son económicamente viables, la deuda adicional no sólo incluye un costo extra debido a la corrupción, sino que la inversión se canaliza hacia proyectos improductivos e innecesarios.

Impacto político.- La corrupción reproduce y consolida la desigualdad social y preserva las redes de complicidad entre las élites políticas y económicas. Respecto a la clase política consolida las clientelas políticas y mantiene funcionando los instrumentos ilegales de control. Respecto al aparato administrativo, perpetúa la ineficiencia de la burocracia y genera formas parasitarias de intermediación. Todo esto conduce a la pérdida de credibilidad en el Estado y a la erosión de la legitimidad necesaria para su funcionamiento adecuado.

Impacto social y cultural.- La corrupción acentúa las diferencias sociales al limitar el papel del Estado como mediador de las demandas de los distintos grupos sociales. Las clases populares o marginales se ven sometidas a un proceso de exclusión social y político ya que la corrupción los aleja del sistema formal y los obliga a acceder de manera informal a sus medios de subsistencia.

Por lo tanto, como consecuencias de la corrupción generalizada podemos indicar:

- Se deslegitima el sistema político. La corrupción de jueces y de legisladores hizo que los peruanos aprobaran masivamente la decisión de Fujimori de disolver e intervenir los poderes del Estado.

- La mala asignación de fondos escasos. "El problema de la corrupción en México”, comentó un funcionario público, "es que aquí se derrocha un millón de pesos para robar mil".

- Se distorsionan los incentivos económicos. Los mejores negocios no dependen de la competitividad de las empresas sino de su capacidad de influir en los responsables de tomar las decisiones sobre las contrataciones. Eso afecta la eficacia de la economía de mercado.

- Se destruye el profesionalismo. En un sistema de corrupción generalizada el interés por los sobornos reemplaza los criterios profesionales.

- Se segrega y desanima a los honestos.

- Se impide la planificación, pues los datos son falsos.

\section{ALTERNATIVAS PARA COMBATIR LOS DELITOS DE CORRUPCIÓN}

En América Latina el problema de la corrupción es considerado uno de los más graves, siendo sus índices de corrupción los más elevados en comparación con los de otras naciones en desarrollo. Dos de los indicadores más importantes que ayudan en la medición de la corrupción son, primero, la participación y rendición de cuentas y, el segundo, es el de la inestabilidad política y violencia. La escasa efectividad que tienen los gobiernos latinoamericanos acarrea problemas de inconsistencia en la aplicación de políticas públicas y en la capacidad para identificar y satisfacer las necesidades de la población. Asimismo, otro factor determinante en los índices de corrupción es el bajo nivel de respeto a las leyes, situándose por debajo del africano. (Marcelo: 2009).

Estando en una nación en donde las prácticas de corrupción cada día se acentúan más, se vio necesaria una regulación. Es en ese sentido que el 16 de noviembre del 2004, el Perú se suscribe a la Convención de Naciones Unidas contra la Corrupción adoptada por la Asamblea General de las Naciones Unidas el 31 de diciembre del 2003. No obstante, el Estado peruano, anteriormente, ya había buscado regular los mecanismos de prevención y sanción de la corrupción mediante la adopción de la Convención Interamericana contra la Corrupción el 06 de abril de 1997, justo a un mes de su entrada en vigor. La razón por la cual se suscribe, en adelante, a la Convención de las Naciones Unidas recae en que esta desarrolla con mayor amplitud los instrumentos de lucha contra la corrupción así como las medidas de naturaleza preventiva, de naturaleza sancionadora y de índole procesal.

Sin embargo, cabe indicar que este instrumento se incorpora al derecho nacional de manera auto- 
mática, en base al artículo $55^{\circ}$ de la Constitución, el cual especifica que todos los tratados que suscriba el Estado peruano formarán parte del derecho interno. Evidenciándose así que el derecho nacional se acopla al sistema monista, uno de las primeras posibilidades sobre las cuales los Estados pueden optar al momento de legislar en el Derecho interno. (Rodríguez, et al. 2012)

Para este estudio, el derecho internacional no tiene validez directa sobre el derecho nacional en tanto de que este no lo haya incorporado mediante el mecanismo adecuado previsto en el ordenamiento jurídico interno. No verá al derecho internacional y al orden jurídico interno como un todo, sino como dos cuerpos totalmente distintos y separados razón por la cual se requerirá de una regulación especial que lo reconozca como parte del derecho interno, de lo contrario no tendrán validez en la sociedad. Otro punto gravitante es el de determinar su jerarquía dentro del ordenamiento peruano. Frente a este problema se distinguen dos posturas sostenidas por doctrina nacional: una que, por un lado, defendía el rango constitucional de los tratados y otra, que de forma antagónica, propugnaba el rango legal de estos.

\section{MEDIDAS GENERALES DE PREVENCIÓN}

Aquellos delitos que perjudiquen a los derechos humanos serán la prioridad para el Estado, el cual deberá cumplir con el respeto y la garantía de éstos. El Estado respetará los derechos humanos en cuanto se mantenga impedido de realizar actos contrarios a ellos, y los garantizará permitiendo a toda persona el goce y ejercicio de los mismos, así como también le corresponderá el papel de prevenir, investigar y sancionar todo acto que los lesione.

Estas obligaciones se derivan de las normas y acuerdos internacionales como de las disposiciones de derecho interno, como en el caso peruano "tenemos el artículo $44^{\circ}$ de la Constitución de 1993 establece como una obligación del Estado «garantizar los derechos humanos». Se trata de una mención general, prevista en un artículo ubicado en una sección del texto constitucional que se revisa poco. Además, aparece mencionada junto con otros $\ll$ deberes primordiales del Estado» — expresión que usa la propia Constitución - como defender la soberanía nacional, proteger a la población de las amenazas a su seguridad y promover el bienestar general".

En cuanto a medidas preventivas, la Convención Interamericana contra la Corrupción establece, en su artículo III, las siguientes obligaciones en materia preventiva: (Rojas: 2010).

a) Normas de conducta para el correcto cumplimiento de las funciones públicas.

b) Mecanismos para hacer efectivo el cumplimiento de dichas normas.

c) Capacitación al personal para que comprenda sus responsabilidades y normas éticas que deberá observar en el cumplimiento de las mismas.

d) Sistemas de declaración de ingresos.

e) Procedimientos de adquisiciones públicas y contratación de funcionarios que garanticen publicidad, equidad y eficiencia.

f) Sistemas que garanticen recaudación y control de los ingresos públicos.

g) Normas que establezcan la eliminación de beneficios tributarios a las personas que participen en prácticas corruptas.

h) El establecimiento de órganos de control superior para la prevención y sanción de las prácticas corruptas.

i) Medidas que impidan el soborno de funcionarios públicos nacionales y extranjeros.

j) Medidas para estimular la participación de la sociedad civil y de las organizaciones no gubernamentales.

Estas medidas, de manera más concreta, han sido recogidas y recopiladas en posterioridad por la Convención de las Naciones Unidas contra la Corrupción. Los países que ratifiquen esta Convención de las Naciones Unidas serán llamados Estados Parte, y estarán subordinados a cumplir con sus obligaciones sin que ello afecte la soberanía de ningún Estado Parte y ninguno de los acuerdos que se plasmen en la Convención de conformidad con los principios de igualdad soberana e integridad territorial de los Estados, tal y como lo expresa la misma Convención en su artículo cuarto. Cada Estado Parte actuará de acuerdo a su ordenamiento interno pero de conformidad con 
los principios fundamentales de la Convención, promoviendo medidas políticas y jurídicas que resulten eficaces en la lucha contra la corrupción en conjunto con la participación de la sociedad, para salvaguardar la debida gestión de los asuntos públicos y también de los bienes públicos, fomentando la transparencia y la obligación de rendir cuentas.

Para la prevención del delito de corrupción de funcionarios deben existir órganos que se encarguen de ello estableciendo medidas eficaces y su debida reglamentación que así lo certifique, y para ello la convención establece una serie de medidas de prevención ${ }^{1}$ para ser desarrolladas por estos órganos encargados: La aplicación de las políticas a que se hace alusión en el artículo 5 de la presente Convención y, cuando proceda, la supervisión y coordinación de la puesta en práctica de esas políticas y, el aumento y la difusión de los conocimientos en materia de prevención de la corrupción.

De acuerdo con la mencionada Convención, el Estado parte deberá de dotar de independencia a los órganos encargados de la prevención de los delitos de corrupción de conformidad con su ordenamiento interno para que dicho órgano no sea alterado ni vulnerado por ninguna intervención de índole pública o privada. En conjunto a la independencia como principio rector de la conformación del órgano mencionado, el Estado parte deberá dotar de recursos materiales y la capacitación debida del personal que esté a cargo de él para el cumplimiento eficiente y eficaz de sus funciones.

Una de las medidas de prevención comúnmente practicadas es aquella que sostiene que los actos de corrupción por parte de los funcionarios públicos cesará cuando estos se vean, asímismo, adecuadamente remunerados, en base a una escala de sueldos que se realice de manera equitativa de acuerdo al nivel de desarrollo económico del Estado y de las capacidades y funciones de los servidores públicos².

\section{MEDIDAS DE REPRESIÓN}

Para combatir directamente el fenómeno de la corrupción el Estado debe diseñar una política integral de lucha contra la corrupción el cual puede abordar cinco frentes principales, teniendo como base al modelo colombiano ${ }^{3}$ :

a) El primer paso es determinar las causas del comportamiento corrupto de los actores públicos y privados; es decir, preguntar por qué existe corrupción en el estado y en cada una de las entidades públicas y privadas.

b) Luego viene el análisis del funcionamiento del Estado para establecer qué tipo de estructuras administrativas (o arreglos institucionales) promueven la realización de conductas corruptas.

c) En tercer lugar, la política integral anticorrupción debe abordar el papel de los particulares en sus relaciones con el sector público y con otros particulares, e incentivar el establecimiento de sistemas de autorregulación empresarial y gremial en materia de lucha contra la corrupción; sistemas que prevengan y sancionen la realización de conductas corruptas desde un enfoque privado.

d) En cuarto lugar, es necesario diseñar e implementar modelos culturales transversales al sector público y privado, que sirvan para educar a la ciudadanía en la vigilancia, control y lucha contra la corrupción, y que incentiven conductas transparentes en el Estado.

e) En quinto lugar, la política debe establecer canales para que los particulares conozcan exactamente las actuaciones de cada una de las entidades públicas, su personal, gasto y cumplimiento de metas, ente otras.

Para que una política integral como la esbozada con anterioridad sea eficaz, necesita de estrategias y metas, las cuales servirán de herramientas conceptuales y técnicas para las entidades encargadas de prevenir, investigar y sancionar conductas corruptas,

1 Convención de las Naciones Unidas contra la corrupción, artículo 6, párrafo 1.

2 Convención de las Naciones Unidas contra la corrupción, artículo 7.

3 Consejo Privado de Competitividad. Corrupción, Colombia, p. 228 . <Disponible en: http://www.compite.com.co/site/wp-content/ uploads/2011/11/Corrupcion.pdf

70/ Quipukamayoc | Vol. 22(41) 2014 
no basándose únicamente en la implementación de sistemas de investigación y control ex-post. Si bien la investigación y la sanción de conductas corruptas son importantes, la ejecución de la política integral debería tener presente algunas propuestas específicas $y$ concretas que permiten mantener funcionarios públicos eficientes y honestos, promover la participación de los particulares o de los funcionarios públicos en la identificación de conductas corruptas, e incentivar la transparencia general como medidas preventivas generales.

\section{IMPRESCRIPTIBILIDAD DE LOS DELITOS}

La imprescriptibilidad de los delitos de corrupción actualmente corresponde a una propuesta legislativa ${ }^{4}$ por romper con los límites temporales de la persecución por delito de corrupción de funcionarios públicos en el Perú. Dicha propuesta legislativa comprende una reforma constitucional, exactamente, del artículo 42 de la Carta Magna, la cual solo ampara la duplicación del plazo de prescripción en caso de delitos cometidos en contra del patrimonio del Estado.

En este sentido, esta investigación propone la ampliación del plazo de prescripción de los delitos de corrupción o su imprescriptibilidad, contiene mayor importancia. Tanto así que la Convención de Naciones Unidas dispone lo siguiente en su artículo 29: "Cada Estado Parte establecerá, cuando proceda, con arreglo a su derecho interno, un plazo de prescripción amplio para iniciar procesos por cualesquiera de los delitos tipificados con arreglo a la presente Convención y establecerá un plazo mayor o interrumpirá la prescripción cuando el presunto delincuente haya eludido la administración de justicia”.

Sin embargo, pese a todos los proyectos de ley ya presentados ante la Comisión del Congreso, la propuesta no ha prosperado. Y esto ocurre a pesar de que en los últimos años, el índice de Corrupción ha ido aumentando progresivamente. En el año 2010, el Instituto Peruano de Economía realiza un estudio en algunos países sudamericanos, en el cual, en una escala de 0 - 10, el Perú obtiene una calificación de 3.5 según el Índice de Percepción de Corrupción en
Sudamérica. Quedando así, en cuarto lugar, respecto de países como Chile que ocupa el primer lugar con un 7.2 de corrupción.

Lo lamentable es que en la realidad peruana, se percibe que las medidas que ya se han estado tomando en nuestra legislación para combatir el fenómeno de la corrupción cada día se hacen más inútiles. Día con día se descubren nuevos escándalos de corrupción en los que grandes y altos funcionarios están inmersos, casos como el del gobierno de Alberto Fujimori que hoy en día fue sentenciado por graves delitos de violaciones de los derechos humanos y por delitos de corrupción.

\section{CONCLUSIONES}

1. La corrupción, en su acepción más generalizada, es la contraparte de una acción ética. Con fundamento en la disciplina ética esta investigación concibe a la corrupción como un mal ya que se compone de una serie de actos indebidos por parte de ciertas autoridades políticas.

2. De modo más específico, se define corrupción como el abuso de posición ejercitado por un servidor o funcionario público, con un beneficio extraposicional directo o indirecto (para el corrupto o de los grupos del que forma parte este), con incumplimiento de normas jurídicas que regulan el comportamiento de los servidores públicos.

3. La corrupción tiene una connotación política, pues afecta negativamente al funcionamiento de la democracia y el Estado de derecho, dañando la igualdad política y el bien común. Algunas investigaciones señalan la corrupción como una de las variables causales de tal fenómeno de desafección, pues erosiona la confianza en el gobierno y la legitimidad de las instituciones políticas.

4. Para combatir la corrupción, los países firmaron acuerdos internacionales como herramienta eficaz para ofrecer un marco que evite ese tipo de defraudaciones. Con respecto al tema, podemos considerar la Convención Interamericana contra la corrupción y la Convención de las Naciones

4 Se pueden revisar al respecto los proyectos de ley: 574/2006-CR, 953/2006-CR, 1082/2006-CR, 1567/2007-CR, 1954/2007-CR, 2400/2007CR, 2415/2007-CR y 3711/2009-CR. 
Unidas contra la Corrupción. Asimismo, en el Código penal se recogen una serie de figuras que permiten identificar en qué circunstancias cabe hablar de corrupción.

5. Para combatir los delitos de corrupción, es importante combinar equilibradamente las medidas preventivas y las medidas represivas. En ese sentido, se sugiere que nuestra legislación incluya de modo más perfilado una serie de instituciones que garanticen una vigilancia y sanción más adecuada. Entre ellas sugerimos la imprescriptibilidad de los delitos, la regulación de la muerte civil inhabilitándolo en el desarrollo profesional y personal y el juicio político.

\section{REFERENCIAS BIBLIOGRÁFICAS}

1. AEDO, C. (1995) "Reflexiones sobre la Corrupción”, Serie Ensayo, 17, Programa de Postgrado en Economía, ILADES- Georgentown University.

2. ARROYO GOMEZ, Yudi (2011) Juicio Político en México, como forma de combatir la corrupción de los funcionarios públicos de primer nivel, México: Facultad de Derecho y Ciencias Sociales de la Universidad Michoacana de San Nicolás de Hidalgo.

3. BENAVENTE CHORRES, Herbert y Leonardo CALDERÓN VALVERDE (2012) Delitos de corrupción de funcionarios, Lima: Editorial Gaceta jurídica.

4. BRUGGER, Walter (1969) Diccionario de Filosofía, Barcelona: Herder, pp. 191-192. Voz ética.

5. BUSTAMANTE, Reynaldo (2006) "Un modelo de interrelación entre la moral, el poder y el derecho: El modelo prescriptivo de Gregorio Peces-Barba”. En; BUSTAMANTE, Reynaldo (coord.). Entre la Moral, el Poder y el Derecho. Lima: ARA Editores, pp. 135-140.

6. CARBONELL, Miguel (2010) "Corrupción judicial e impunidad. El caso de México". En: MÉNDEZ-SILVA, Ricardo (coord.). Lo que todos sabemos de la corrupción y algo más, México: UNAM.

7. CARRETERO, Santiago (2010) "Corrupción, Funcionarios públicos y papel de la Deontología”.
En: Revista Telemática de Filosofía del Derecho, $\mathrm{N}^{\circ} 13$ p. 16.

8. MARCELO SZELUBSKI, Jorge. La corrupción: embate a la democracia latinoamericana, Buenos Aires: Universidad de Belgrano, 2009, p.50.

9. MOLINA ARRUBLA, Carlos Mario (2000) Delitos contra la administración pública. Bogotá: LEYER.

10. MONTOYA VIVANCO, Iván (ed.) (2012) Estudios críticos sobre los delitos de corrupción en el Perú, Lima: Instituto de Democracia y Derechos Humanos (PUCP).

11. PARIONA, Raúl (2012) “La imprescriptibilidad de los delitos de corrupción de funcionarios. ¿Medida necesaria para evitar la impunidad?". En: MONTOYA, Yván. Estudios críticos sobre los delitos de corrupción de funcionarios en el Perú, Lima: IDEHPUCP, p. 16.

12. RICO, José María y Luis SALAS (1997) L a Corrupción Pública en América Latina: Manifestaciones y Mecanismos de Control. Miami-Florida: Centro para la Administración de Justicia.

13. RODRÍGUEZ VÁSQUEZ, Julio y otros (2012) Estudios críticos sobre los delitos de corrupción de funcionarios en Perú, Instituto de Democracia y Derechos Humanos de la Pontifica Universidad Católica del Perú, Lima, pp.168-187.

14. ROJAS AMANDI, Víctor (2010) "Los tratados internacionales sobre corrupción”. En: MÉNDEZ-SILVA, Ricardo (coord.) Lo que todos sabemos de la corrupción y algo más, México: UNAM, p. 181.

15. ROWLAND, Michel (1998) "Visión contemporánea de la corrupción”. En: La hora de la transparencia en América Latina. El manual de anticorrupción de la función pública, Buenos Aires: Granica/Ciedla, pp. 31-42.

16. RUIZ-TAGLE, Pablo (1998) "Incorruptibles y corruptos”. En: URZÚA Raúl y Felipe AGÜERO (eds.), Fracturas en la gobernabilidad democrática, Santiago: Centro de Análisis de Políticas Públicas, Universidad de Chile, p. 220. 
17. VÁSQUEZ, Rodolfo (2010) “Corrupción política y responsabilidad de los servidores públicos”. En: MÉNDEZ-SILVA, Ricardo (coord.). Lo que todos sabemos de la corrupción y algo más, México: UNAM, p. 216.
18. VILLORIA, Manuel y Fernando JIMÉNEZ (2012) La corrupción en España (2004-2010): datos, percepción y efectos. En: Revista Española de Investigaciones Sociológicas, $\mathrm{N}^{\circ} 138$, abril-junio, p. 114. 